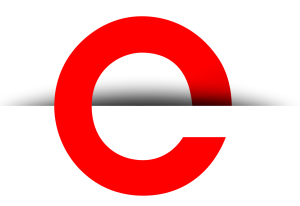

U T S

e PRES S
Gateways:

International Journal

of Community

Research and

Engagement

Vol. 14, No. 2

December 2021

(c) 2021 by the author(s). This is an Open Access article distributed under the terms of the Creative Commons Attribution 4.0 International (CC BY 4.0) License (https:// creativecommons.org/licenses/ by/4.0/), allowing third parties to copy and redistribute the material in any medium or format and to remix, transform, and build upon the material for any purpose, even commercial, provided the original work is properly cited and states its license.

Citation: Haarman, S., and Green, P. M. 2021. Considering Power in Community-Based Research: Shifting Toward New Pedagogical Approaches with a 'Public Work for Public Things' Framework. Gateways: International Journal of Community Research and Engagement, 14:2, 1-13. http:// dx.doi.org/10.5130/ijcre. $\underline{v 14 i 2.7754}$

ISSN 1836-3393 | Published by UTS ePRESS I http://ijcre. epress.lib.uts.edu.au
PRACTICE-BASED ARTICLE

\section{Considering Power in Community-Based Research: Shifting Toward New Pedagogical Approaches with a 'Public Work for Public Things' Framework}

\author{
Susan Haarman ${ }^{1}$ and Patrick M Green ${ }^{1}$ \\ ${ }^{1}$ Center for Engaged Learning, Teaching, and Scholarship, Loyola University Chicago, Illinois,
} USA

Corresponding author: Susan Haarman; shaarmanQluc.edu; Patrick M Green, pgreenQluc.edu

DOI: http://dx.doi.org/10.5130/ijcre.v14i2.7754

Article History: Received 08/06/2021; Revised 02/09/2021; Accepted 14/09/2021;

Published 12/2021

\begin{abstract}
One of the fundamental questions of power in the pedagogy of community-based research (CBR) is who gets to decide what is research worthy and what is the focus of CBR questions? The reality of the power imbalance in community-based research and learning is often reflective of a systemic disengagement with the broader community. Even when instructors and administrators are intentional in how they solicit feedback or think through the impact of their work, they may not know the neighbourhood. Prioritising the voice of community partners does not provide a simple solution, as the individuals we work with to organise community-based learning opportunities may not be residents of the neighbourhood.

This article adopts a theory-building approach to this crucial question. Building on the work of Boyte (2014) and Honig (2017), community-based research is reoriented as 'public work for public things' (Haarman 2020). After establishing the 'public work for public things' framework, the article explores how this new framework impacts collaborative research by addressing the power differential and creating new lines of inquiry - specifically the practice of 'elicitation of concerns'. Through the lens of critical service-learning pedagogy (Mitchell 2008) and a practitioner-scholar framework (Lytle 2008; Ravitch 2013; Salipante \& Aram 2003), we then interrogate two community-based research courses we have recently taught, examining how a 'public work for public things' approach would have altered the course and its methods.
\end{abstract}


U T S

e PRES S

\section{Keywords}

\section{Community-Based Research; 'Public Work for Public Things'; Community-Based Learning; Elicitation of Concerns}

\section{Introduction}

In community-engaged teaching, learning and scholarship, one of the most common models referenced is community-based research. Teaching a community-based research course, however, is often determined by a higher education institution's priorities, whether it be disciplinary approaches of a specific course, community projects of a specific instructor, or pre-determined strategic goals of the institution. The community or partner organisation representative of the community may be brought in once the focus has been decided, but they may have little impact at the beginning of the process. The literature around community-based learning pedagogy, specifically through the lens of critical service-learning, suggests the need to engage in more equitable approaches with community partners regarding course design. This leads to the fundamental question of power in the pedagogy of community-based research: Who gets to decide what is research worthy and what is the focus of CBR questions?

The reality of the power imbalance in community-based research and learning is reflective of a systemic disengagement with the broader community, even when instructors and administrators are intentional in how they solicit feedback or think through the impact of their work. The institution of higher education may not know the neighbourhood - specifically public places and things where people gather to exchange ideas, information, knowledge and experiences.

In the face of this challenge in teaching community-based research, it may seem simple to just default to prioritising the voice of the community partners with which we work. However, if the community partner is a non-profit or neighbourhood business or institution, that solution may raise many questions around power and representation. Especially in the case of non-profits, the individuals we work with to organise community-based learning opportunities may not be residents of the neighbourhood. In our own surrounding neighbourhood of Rogers Park in Chicago we face this challenge. The neighbourhood is exceptionally diverse, both racially and economically, and has been the primary resettlement neighbourhood for refugees since the 1940s. As a result, the neighbourhood is home to several community organisations and agencies that serve the refugee population, most of whom we work with. However, few of these organisations are staffed by individuals who live in the neighbourhood and fewer still include refugees on the staff or in leadership roles. While major issues of language fluency and resources can justify this discrepancy in valid ways, a lack of critical awareness of the power dynamics can potentially enable community partnerships to perpetuate marginalisation.

Highly diverse neighbourhoods also provide a challenge when priorities range widely across groups. The problem of 'whose voice counts' is often amplified when different populations in a community have different needs and desires. While a traditional Asset Based Community Development approach would simply suggest that you haven't talked to the right people or you need to work with a smaller subsection of a population, the reality of engaging in civic learning and projects rarely allows you to do so, especially when resources are scarce. Additionally, when engaging staff members to prioritise community-based learning opportunities, many are working from a narrow focus of their own agency's priorities and goals. This presents the ongoing dilemma of whether or not community-based learning courses focused on communitybased research are actually community-driven or community-prioritised.

In this article, we explore a theory-building approach to teaching community-based research courses. Building on the work of Boyte (2014), Honig (2017) and Haarman (2020), we focus on a reorientation of community-based research courses around a public problem-solving framework, which focuses on 
undertaking collaborative research through the lens of 'public work for public things' (Haarman 2020). Through the lens of critical service-learning pedagogy (Mitchell 2008) and a practitioner-scholar framework (Lytle 2008; Ravitch 2013; Salipante \& Aram 2003), we then explore the practice of teaching such courses by interrogating two community-based research courses we have recently taught. How does 'public work done on behalf of public things' inform collaborative research and learning in practice and through pedagogy? How can Honig's understanding of public things and Boyte's model of public work change the way we approach community-based work? After establishing the 'public work for public things' framework in its formative stages of development and applying it to our courses, we explore how this new framework impacts collaborative research by addressing the power differential and creating new lines of inquiry as it needs to be tested in practice. Such interrogation leads to necessity for new points of entry into community-based research methodologies, rooted in community wisdom and acknowledgement of 'public things', as starting places for research questions.

\section{Public Work for Public Things}

The Sphinx's riddle of 'whose voice' is most relevant when considering how generation of communitybased learning priorities may lead to unfocused efforts, slapdash partnerships and inaction. Rather than fixating on 'who' has the most authority to decide, the authors of this article believe that the question of the broader purpose of these efforts must be recast. We must step back and reframe the work of communitybased learning as what Harry Boyte calls the public work of education, rather than the simple acquisition of knowledge (albeit in conjunction with community partnerships). A public work frame takes a broader and more active view of the voices that drive community-based learning priorities and is more inclusive of the voices in the conversation rather than pitting them against one another.

Boyte and Kari (2000, p. 57) state that civic education must be recast as the public work of education. Public work can be defined as 'self-organized efforts by a mix of people who create things, material or symbolic, whose value is determined by a continuing process of deliberation' (Boyte \& Kari 2000, p. 57). Public work is rooted in a deliberative process with no one community, person or institution controlling its direction in totality. To progress, people must remain in conversation with one another and work towards a mutually agreed upon common good. Traditional power dynamics are challenged because of the mutuality that serves as a framing element of this approach. A public work cannot be accomplished by one constituency, instead calling for cooperative approaches that demand universities and other traditional power holders create more open relationships with community partners and others.

Boyte emphasises that public work must be supported by elements of deliberation because a public work's power is rooted in its capacity to draw a variety of different ideological positions into a common project. 'A public work approach does not eliminate the fierce debates about distributive justice or questions of values, but it allows people with great differences on such issues to work together on public tasks of large significance' (Boyte \& Kari 2000, p. 57). Deliberative public work also helps participants come to value each other's perspectives when they reflect on the importance of what they were able to do together.

\section{Public Work and Deliberation}

In Boyte's model, the back and forth of deliberative communication becomes a crucial tool in public problem solving and the creation of publics. Groups can leverage different voices and go through the intentional process of offering alternative plans and thoughtful consideration of consequences, gaining deeper insight and the potential for better and more widely acceptable ways of proceeding. By opening up a wider sense of the possible ramifications of both the public problem and its possible solutions, individuals gain a better sense of how consequences affect them. 
When embracing a public work approach to community-based learning, university work should be in service to the community AND in continual conversation with the community. We must shift away from a simplistic and legalistic approach to civic engagement and towards a more deliberative and democratic frame. This university would then cease to understand itself as apart from the broader community and who John Dewey called 'those who wear the shoes' - individuals with direct experience of reality. Beyond implementing effective and dynamic pedagogy, this university would claim a public work mission, sharing their expertise with those without the resources or capacities to fully analyse and resolve public problems. Because public work arises from deliberation, the university would form priorities for action in conversation with the larger community, being attentive to an ever-changing conversation about what was needed for the greater good, and not just the institution's interests. This university would understand itself as a part of a larger public, one of many actors seeking to implement and live into the ideal of democracy.

Boyte (1991) believes that key to this is reframing political involvement as more than voting and governmental procedure and shifting towards a conception of civic engagement as addressing public problems. Framed now as public concerns in which their voices are needed alongside those of the wider community, students would be inspired to join in collective action. This would not resolve difference, socioeconomic inequalities or the pernicious white supremacy that is at work in many of our communities and our institutions, but it would shift community-based learning away from a zero sum gain of whose voice wins and instead move towards a frame, 'in which diverse groups learn to work together effectively to address public problems, whether or not they like one another personally' (Boyte 2014, p. 3).

\section{What Guarantees Public Work Reflects Public Concerns?}

However, more voices, even when they are in discourse, does not guarantee that a process will be diverse or any more likely to accurately respond to neighbourhood needs. Universities may have strong deliberative relationships with non-profits that do not represent the members of the community in values, identities or goals. Particularly in diverse communities, it can seem like the only thing tying groups of people together is a zip code. This tension calls for a deeper reflection on the places and points where communities do come together and urges that community-based learning begin there.

We may find a secure point from which to begin in Bonnie Honig's (2017) conception of public things. In her work, Public Things: Democracy in Disrepair, Honig uses the idea of 'public things' as a catalyst for democratic action. This concept helps illuminate where some of the potential for deeper political engagement through deliberative pedagogy in community comes from. Honig intentionally does not precisely define public things, but she does say that they are subject to public oversight and objects of a public's shared value and care - things like swimming pools, sewers, land, schools, and even public telephone booths. Honig calls public things a necessary, if not sufficient, condition for healthy democracy concentrating and focusing citizens' attention and galvanising their efforts. They help to form publics, spurring collective action and even helping establish identity. '[Public things] constitute us, complement us, limit us, thwart us, interpellate us into democratic citizenship' (Honig 2017, p. 25).

\section{Community-Based Research and Public Things}

Community-based research regularly places students in the orbit of public things. For instance, students at our university normally utilise Chicago's 'L' trains for pleasure or recreation. Now they may find themselves taking the train to community sites. This initial shift of route allows them to see different residents of Chicago, redefining their own sense of the make-up of the city. The common experience of the train may become a point of conversation with individuals different from themselves, with whom they previously would not have interacted. As students learn about their acquaintances' long commutes to work or 
experiences with poorly serviced bus routes, their understanding of how the Chicago Transit Authority (CTA) functions in the lives of Chicagoans broadens.

Students may find that they have come to show care and concern about the CTA, which invites a different level of engagement with their community. Bus route placement becomes something to which they pay new attention. They may begin to decry the poor conditions of train carriages on primarily south and westbound routes. There is a subtle shift and these students are drawn into a larger public that is centered around the CTA as a public thing. Honig $(2017$, p. 28) says this occurs because a public things framework has people 'first asking not "who are we?" but rather "what needs our care and concern?"

Honig's framework of 'What needs our care and concern?' can actually encourage a deliberative approach that empowers students who otherwise might have found themselves conflict avoidant and unlikely to engage in discourse around power structures or politics. Although it is ultimately a question of class and economic inequality, the students who are now concerned members of CTA ridership are brought into the question through the lens of access to a public good. Students previously resistant to broader questions of privilege and power may be more likely to advocate around the public thing they have come to care for. Through public things, the self-avowed apolitical are more likely to begin to utilise or make demands on power structures, rather than not acknowledging their own capacity and access to power (Haarman 2020).

Public things are named and claimed as valuable by a community. They become a flashpoint for public action and concern. They also become an expression of a community's ideals and values. $\underline{\text { Honig (2017) }}$ makes it clear that public things are never simply neutral, but instead facilitate action and space through which communities can manifest their core concerns. Action on behalf of and around public things is then an expression of action that interrogates the use of power.

In this regard, public things become an ideal site for public work because of their importance and their relative permanence. Honig (2017) says part of the necessary ongoing work of democratic citizenship is coming together to construct public things, maintain them and establish their status as the transitional objects of democratic life. They also yield a level of permanence that encourages us to think about the ways in which the communities we live in and the work we are engaged in are more permanent than we are. Students' work in the community will likely end when the course does. But the CTA and the Chicago Public School system remain, continuing to be sites in which democratic questions are engaged. Community-based researchers may realise their own impermanence in this work, undercutting the troublesome 'savior' tendency that can come from community-based work. Recentring community research on the needs and hopes of citizens, which is refracted through public things, will open up an approach from which meaningful public work can be pursued on behalf of public problems (Haarman 2020). Rather than continually wondering about whose agenda community-based research has advanced at the expense of another group in a neighbourhood, grounding the work in public things allows space for multiple voices.

\section{A Methodology of Public Things}

A public things approach asks practitioners to think differently about the role of multiple voices when setting the agenda for community-based research. It centres the community as a physical space in which a cross-section of perspectives and needs interact, and urges an approach to community-based research that centres dialogue and citizenship. Universities and non-profit staff will not be the only sources of important questions.

A public work for public things approach also presents new potential lines of inquiry for communitybased research. The authors advocate using an elicitation of concerns approach to bring the priorities of the community to the surface. Practitioners and researchers would ask questions and seek to understand community concerns and priorities through public things; they would practise being in and with public spaces. Those seeking to undertake community-engaged work may first go to public things and 
U T S

e PRES S

observe, participate and interact with people there. Rather than just surveying individuals at high-traffic neighbourhood nexuses, taking a public things approach means that practitioners would go to public things to listen, observe and converse with members of the community.

By using an open inquiry method, practitioners could perform an elicitation of concerns, inviting community members to share what they experience as the salient issues and priorities in the community as they see them. The inquiry would begin by locating questions around the usage or importance of the public thing (e.g. the condition of public transit lines or park usage), and then allow the community member to expand beyond that. This methodology differs from traditional open town hall meetings in that community members are met where they are physically, rather than asking them to travel to a city hall or university. In addition, the nature of public things is that they build and construct community around them, usually from diverse identities. As a result, eliciting concerns in and through public things allows for a broader level of representation and commitment to a community than a simple survey might.

While one element of elicitation of concerns is active, another is more passive. This involves facilitation through public things. Just as a public thing is used as a springboard to help community members actively share their concerns, observation of how individuals interact with a public thing also becomes a generator of potential concerns. Practitioners can observe that a train station in a neighbourhood does not have ADA access or that a library has become a de facto meeting space for running groups or teens studying after school. Rather than trusting either their own 'expertise' or simply taking the word of one local non-profit or faith community leader, practitioners can build up a picture of the experiences and concerns of community members from how they are interacting with public things. Public things then become a new lens through which to listen for and examine public concerns and identify potential for partnership and research into daily concerns.

Elicitation of concerns is not solely deficit focused in its approach. Too often, community-based research has been deficit and damage focused, highlighting only what was perceived to be broken in a community. Even if its end goal was to serve an ameliorative purpose, this research framing reduces community members to victims, divorcing them from agency and personal power. It is also reductionary in approach, failing to highlight the diversity of both need and experience within communities.

While the process of an elicitation of concerns brings to the surface issues that community members believe need to be addressed, it is often the public things that ground the elicitation to serve as flash points for community care in addition to concerns. A school library may be a beloved public thing in a community, and an elicitation of concern there may reveal a common drive in a diverse community to create spaces where all children have access to the arts. This sifting through an elicitation of concerns mirrors Eve Tuck's (2009) distinction of desire-based research. Desire-based research focuses on the complex lived realities of communities, with particular focus on their self-determination. A public work for public things approach allows more space for community-based research to follow the desires and joys of a community, not just its struggles. When broader collaborative work is rooted in a public thing, there are typically more tangible manifestations of community desire. This is in contrast to community-based research that just examines a problem to solve.

To provide an example of this essential nuance, imagine a community-based research course without a public work for public things frame that focuses on issues of literacy in a community based on conversations with a few non-profit organisations. This course may design reading and literacy interventions that respond to the specific needs of the community, but the narrative of this community-based research stops at a deficit place. This is a community struggling with literacy and in need of essential assistance. In contrast, imagine if the same course used a public work for public things framework and performed an elicitation of concerns at the well-loved local library. The course would still surface the need for literacy interventions, but it would now be a concern shared not only by non-profit staff who run programs there, but also by local parents 
and their children who patronise the library. However, it is through the library - the public thing - that it is revealed that this need for literacy also comes from a place of joy and desire. The elicitation of concerns process allows community-based researchers to see parents lauding the essential role that weekly story-time programs play in the life of their children or teenagers as they pour over graphic novels together to try to design their own. As a result, desires can drive community-based research as much as deficits.

The public work for public things framework clearly alters the approach to community-based research. The challenge to building the elicitation of concerns process into the pedagogy of community-based research lies within issues of power. As community-based research often emphasises a collaborative approach with the community, this approach challenges it to be even further driven by the community in potentially broader ways. The process of elicitation of concerns is dynamic in nature, with a large emphasis on openness to emergent themes and questions. As a result, community partners could participate in this process alongside community-based scholars. Because much of the work also includes observation and non-scripted inquiry, community members could bring important additional lenses of observation and social capital that would encourage more communication and conversation. There are also tremendous research possibilities around how this methodology could be applied to challenge traditional structures of power around knowledge generation.

Elicitation of concerns, as a method, also has tremendous potential in highly diverse communities. As mentioned previously, community-based scholars often work with specific community-based agencies or population groups within a community. Especially in diverse communities, these groups may have interests and priorities that differ from others. While these may be essential and valid priorities, it can be easy to take a narrow view of how a broader community is engaging with an issue or miss an essential minority view. For instance, in the aforementioned highly diverse neighbourhood of Rogers Park, the issue of school resource officers (SRO) in the local high school became a focus of intense debate in the wake of George Floyd's murder. While most students, local parents and community members did not want to continue to employ an SRO, there was notable dissent from refugee parents (who make up 20 percent of the school population) in strong favour of keeping the officers. An elicitation of concerns at the school would have likely surfaced this narrative, while working with the numerous nonprofits that serve students and attending public forums may not have done so. Elicitation of concerns at and through public things promotes and requires a critical awareness of power and dynamic engagement with it.

We turn now to our practice of teaching community-based research courses through a critical servicelearning lens.

\section{Exploring Power in Community-based Research Best Practice through a Critical Service-Learning Pedagogy Lens}

Community-based research best practice is usually situated in the literature of service learning, commonly referred to as community-based learning, and is heavily focused on practice and pedagogy. The robust canon of literature on community-based learning has certainly provided rich material focusing on the most promising practices and strategies for the pedagogical approach to community-based learning. In the design of community-based learning courses and experiences, the focus has been on the community-based activity, or on the community partnership, but issues of power often have not been highlighted or emphasised (Heinrich \& Green 2020; Mitchell 2008).

Perhaps the most significant shift in the literature is the scholarship of Tania Mitchell (2008), explaining how critical service-learning pedagogy is differentiated from traditional service-learning. In her work, she shifts the narrative from a charity model to a social change/social justice model, her analysis of the literature revealing three themes that distinguish a critical service-learning pedagogy: a social change orientation, 
U T S

e PRES S working to redistribute power, and developing authentic relationships. Mitchell connects critical servicelearning pedagogy directly to issues of power:

A critical service-learning pedagogy names the differential access to power experienced by students, faculty, and community members, and encourages analysis, dialogue, and discussion of those power dynamics. Without looking at access to social power and the role of power (or the lack of power) in determining who receives service as well as what services are provided, the potential of using service-learning as a pedagogy that brings society closer to justice is forfeited (Mitchell 2008, p. 56).

The critical service-learning pedagogy clearly articulates a critical consciousness of both learning design and learning outcome for community-based learning courses.

The emphasis is on an intentional design of the experience and the course that acknowledges the power differential of the community members, faculty and students. As Mitchell examines the classroom component and community component of a critical service-learning pedagogy, she concludes:

Developing experiences with greater attention to equality and shared power between all participants in the service experience and challenging students to analyze the interplay of power, privilege, and oppression at the service placement and in their experience in that placement will ensure that a critical service-learning pedagogy questions and problematizes the status quo. (Mitchell 2008, p. 62)

The implications of this critical service-learning pedagogy have led to strategic pedagogical and course design approaches to community-based learning courses that include working with community partners as co-educators. This is the approach we applied to the development of our community-based research courses.

Community-based research became a distinct form of community-based learning, and emerged as a significant model of community-based learning (Heffernan \& Cone 2003). Strand et al. (2003) provided a strong foundation for framing community-based research in the context of the academy as a response to such factors as criticism of higher education as unresponsive to the needs and priorities of the community, as well as the renewed effort to build students' civic capacity through community outreach efforts. In this foundational work, Strand and colleagues established the core pedagogical principles of community-based research $(\mathrm{CBR})$ :

- $\mathrm{CBR}$ is a collaborative enterprise between academic researchers (faculty and students) and community members

- CBR validates multiple sources of knowledge and promotes the use of multiple methods of discovery and dissemination of the knowledge produced

- CBR has as its goal social action and social change for the purpose of achieving social justice (Strand et al. 2003 , p. 8$)$.

Although various models of community-based research exist historically, the explicit connection between people in the community educating themselves and conducting/participating in research to foster social change is a consistent theme (Strand et al. 2003). As we sought to employ these principles along with a critical service-learning lens, our community-based research courses were shaped by these specific promising practices. If we apply the public things framework, does the course design alter how we partner and work in community-based learning courses, such as community-based research? Does the elicitation of concerns as a prioritisation process through public things change how we design and teach community-based research? 
U T S

e PRES S

\section{A Practitioner-Scholar Analysis of Community-Based Research Pedagogy and Practice}

As practitioner-scholars working in the community engagement field for the past two decades, the emphasis on elevating community voice is not new to us or our practice. The literature around community-based learning has emphasised and called for an increase in community voice and participation in communitybased teaching, learning and research for the past two decades. Stoeker et al. (2009) asked whether community voice was considered in the institutional practice of service-learning in higher education and, as referenced above, Mitchell (2008) proposed a critical service-learning framework that would elevate justice, social change, power and authentic relationships, as well as the role the community plays. Yet, the proposition of approaching community-based research and teaching via a public things framework is essentially changing the critique.

The public things framework emphasises more than the role the community plays in community-based teaching and research: location and context are central to the dialogue. This approach fundamentally changes how we access community voices, acknowledging the power differential that exists when university faculty or staff interact with community members. By shifting the dialogue from raising awareness about community voice to accessing community voices in public spaces, this framework elevates community priorities through an elicitation of concerns. In essence, the role of community and accessing community voices within public spaces are central to issues of power in the public things framework.

We wanted to interrogate this approach within our own community engagement practice through the critical service-learning pedagogy lens. As community engagement professionals, we serve as educational administrators who facilitate community-based learning programs, faculty development programs and curriculum development resources. We also teach a variety of community-based learning courses and serve as third space professionals (Whitchurch 2013), blurring the spaces between academic administration and faculty, between student learning and development and faculty development, and between classroom and community. We are boundary spanners, identifying as both scholars and practitioners in the field (Green, Eddins, Berkey \& Meixner 2018; Whitchurch 2013). Our positionality as practitioner-scholars informs our theoretical framing of this work, and we draw upon the reflective practitioner lens alongside critical inquiry on practice (Ravitch 2014; Schon 1983).

Through the lens of the practitioner-scholar framework and critical service-learning pedagogy, we explore two community-based learning courses we co-instructed with community partners over two different semesters at our university. The EXPL 290 and EXPL 291 courses are three-credit service-learning courses offered as an elective and meeting the Engaged Learning University Requirement at the institution. Entitled Seminar in Community-based Service (EXPL 290) and Seminar in Community-based Research (EXPL 291), the courses engage students in a community-based research project with a single partner organisation. The project is developed prior to the beginning of the semester with the partner organisation and the instructors. The research questions emerge from multiple meetings with the partner, identifying their priorities and projects requiring research. The following intentional planning process was followed in the creation of the community-based research courses through these steps:

Initial meeting to invite a partner to serve in the role of co-educator. The initial meeting with each partner began with a visit to the community site, intentionally situating us within the community context in which we wanted students to work. Through previous meetings and conversations with each partner, they had already expressed interest. This initial meeting achieved two goals: (1) frame for the partner that we approach this work through the lens of co-education, and ask them to be a co-educator throughout the process, and (2) dialogue about possible community-based research projects to which the students could contribute. 
U T S

e PRES S
Creation of a research project. The multiple rounds of communication and dialogue via in-person meetings, phone conversations and/or email communication varied, but the dialogue process led us to articulate a project.

Syllabus description. We documented the project at these meetings so that we shared the same language, identified the intended deliverables, and described the process with a level of specificity, while also leaving room for some flexibility.

Site visit and community context. We intentionally started the course with a site visit (usually first or second class) and assignments related to the community context. This allowed students to connect immediately with the organisation and understand the context of the community in which it resides and offers services.

Scheduled class session in community context. There were several class sessions which we taught at the community site in an effort to extend learning beyond the four walls of the classroom and into the community. Our learning space was often a room located at the non-profit organisation.

Validation check-in meetings about the research project. We built several check-in meetings into the course schedule, and naturally check-ins occurred with the partner scheduled to be in the classroom or the class meeting in the community.

Summative presentation of project findings to partner and/or designated audience. Near the end of the course, students were assigned to present the final deliverable, whether it was a report, slide show or visual artifact.

The process throughout these courses was an intentional approach, centred in critical service-learning pedagogy, so as to centre the community voice and address the community organisation representative as both partner and co-educator in the process. Yet, what would the course have looked like had we approached the course design from a public things framework? Where would there have been space for an elicitation of concerns?

\section{Interrogating our Practice: Developing New Points of Entry}

Approaching our course development through the lens of a reflective practitioner ( $\underline{\text { Schön } 1983}$ ) and drawing on the scholar-practitioner framework of critical inquiry (Lytle 2008; Ravitch 2014), we interrogate the course construction and partnership approach to our community-based research course through the public work for public things framework. While the public work for public things orientation was not a consideration for the initial design or aim of the partnership, we do believe that self-reflexivity about how this approach could have illuminated other issues or possibilities is important. More than an exercise in methodological Monday morning quarterbacking, the push to consider how a different framework would have impacted the approach to the partnership could reveal blind spots, unrecognised systemic dynamics and roads not taken. Our inquiry approach demonstrates the need to critically examine issues of power from the beginning of the design process.

Our partnership approach, as previously detailed, involved the co-construction of the course, from learning outcomes to the research question and project implementation. Yet, we may not have started in the right place. For example, one semester we partnered with a faith-based refugee resettlement program, associated with a large non-profit organisation. We taught the course on campus one week and at the non-profit organisation's meeting room space in the community the following week. Another semester we partnered with a Quaker elementary school located in our campus neighbourhood community. Although 
these courses were often co-taught by the non-profit staff members and at the location of the non-profit organisation (in the community), they did not occur in or through public things. Who we met and heard from was still essentially funnelled through the non-profits. Thus, the community-based research questions and projects emerging from these courses were disconnected from public things.

The lack of connection to the public work for public things approach meant that our partnership was disconnected from the very community we (and the school) sought to partner. We had limited contact with the refugees or the parents and children of the Quaker school. We did not hear from them, nor their experiences, concerns, perspectives or insights. There was no elicitation of concerns, which the public things approach challenges us to pursue in the context of community engagement work. Although a list of potential questions may be formulated to approach an elicitation of concerns, we suggest a more practical approach as questions may emerge from those in power. Specifically, planning for an elicitation of concerns involves:

1. Identifying public places within the context of the community.

2. Generating questions specific to the public thing for the elicitation process. If already engaged with additional community partners, this process should be shared with them as well. These questions are not to be seen as exhaustive or prescriptive of inquiry that occurs during the elicitation of concerns.

3. Developing an action plan to employ the elicitation of concerns.

4. During elicitation of concerns, participants should practise critical listening and observation, allowing for emergent themes to arise as individuals interact with one another through and with the public thing. This observation is meant to be done in a participatory and engaged way, recognising the observer's own interactions with the public thing.

In reflecting upon our courses, the power differential was, in fact, shifted from the university to the nonprofit partner, which suggests a need for a critical examination of power in the design of courses and partnerships. As we reflect on our teaching of these community-based research courses, utilising best practice, it appears that the community members were not empowered. Power and resources shifted from one narrow set of hands to another and still remained separated from those on whom the research was focused.

The practical implementation of this framework offers an invitation to faculty educators, along with community engagement professionals across higher education institutions, to employ the framework in their practice. Further exploratory research on deliberative processes involving citizens may help to further develop the framework, as well as test it, and other key implications emerging from our inquiry. There are many professional organisations already dedicated to place-based community engagement and research involving institutions of higher education. While a place-based framework and a public things perspective share similar approaches, they are not synonymous. The public things framework is rooted in the facticity of the public things themselves. They are not only a geographic location, but also an object that individuals interact with. Beyond that, they serve as catalysts for concern and community building, bringing people together. They are also often symbols of larger structural frames (e.g. a bus station is both the physical station and a symbol of the larger public transportation system), participating in the larger reality to which they also point. Place-based approaches could utilise a public things framework for inquiry. The articulated differences, commonalities and potential for synergy between these two approaches is an area that needs further study.

Employing this framework in practice may inform and help to evolve the framework as we deepen our understanding of community-engaged work with and through public things via an elicitation of concerns. To start with, the focus of the community-based research could be an elicitation of concerns within a specific community context. From working with local government officials, educational institutions, libraries, public 
U T S

e PRES S parks and local museums in employing the public work for public things framework, it is clear there is room for further research, as well as an opportunity to better serve the communities we seek to engage.

\section{Conclusion}

The elicitation of concerns, the inquiry approach to providing community members with the opportunity to share their concerns and priorities at and through public things, suggests a different pedagogical approach to teaching community-based research courses. In addition, the public work for public things framework has significant implications for partnership work. Elevating the community voice and allowing the community to drive research on their articulated concerns and priorities, while also allowing public things to provide the environment for priorities to emerge, is imperative. When public things are introduced to the broader vision of the public and work being done by universities and community organisations, neither is able to centralise power so easily. A continual return to the common space in and through which communities are connected, interact and live will provide more voices to the necessarily deliberative process of public work. It will also ground the work in service to the daily reality of community - not necessarily the specific agenda of a university or non-profit organisation.

More significantly, with the current call for place-based community engagement, the public work for public things approach challenges us to frame 'place' differently. It may also reveal a broader range of opinions and issues, and potential coalitions previously unconsidered by community members themselves. Inquiry in public spaces and through public things may encourage an empowered approach by community members to engage as full partners in community-based research. Situating community members and place-making in local public spaces will require community engagement professionals to approach our work differently. It will require us to begin our work through public things and listen to those who gather there.

\section{References}

Boyte, H 1991, ‘Community service and civic education’, The Phi Delta Kappan, vol. 72, no. 10, pp. 765-67.

Boyte, H 2014, 'Deliberative democracy, public work, and civic agency', Journal of Public Deliberation, vol. 10, no. 1, p. 15. https://doi.org/10.16997/jdd.190

Boyte, H \& Kari, N 2000, 'Renewing the Democratic spirit in American colleges', in Civic Responsibilities and Higher Education, Oryx Press, Westport, p. 37.

Green, P, Eddins, E, Berkey, B \& Meixner, C 2018, 'Exploring the borderlands through collaborative inquiry: A narrative introduction', in B Berkey, C Meixner, P Green \& E Rountree (eds), Reconceptualizing faculty development in service-learning / community engagement: Exploring intersections, frameworks, and models of practice, Stylus Publishing, Sterling, VA.

Haarman, S 2020, 'Public work for public problems', Philosophical Studies in Education, vol. 51, pp. 117-29.

Heffernan, K \& Cone, R 2003, 'Course organization', in Introduction to Service-Learning Toolkit: Readings and Resources for Faculty, Campus Compact, Providence, RI, pp. 105-110.

Heinrich, W \& Green P 2020, 'Remixing approaches to experiential learning, design, and assessment', Journal of Experiential Education, vol. 43, no. 2, pp. 205-23. https://doi.org/10.1177/1053825920915608

Honig, B 2017, Public things: Democracy in disrepair, 1st edn, Oxford University Press. https://doi.org/10.5422/ fordham/9780823276400.001.0001

Lytle, S 2008, 'Practitioner inquiry and the practice of teaching: Some thoughts on "better" research in the teaching of English, vol. 42, no. 3, pp. 373-79. http://ezproxy.msu.edu/login?url11/4https://search.proquest.com/ docview/215344856?accountid $1 / 412598$ 
Mitchell, T 2008, 'Traditional vs critical service-learning: Engaging the literature to differentiate two models', Michigan Journal of Community Service Learning, vol. 14, no. 2, pp. 50-65.

Ravitch, S 2014, 'The transformative power of taking an inquiry stance on practice: Practitioner research as narrative and counter-narrative', Penn GSE Perspectives on Urban Education, vol. 11, no. 1, pp. 5-10.

Salipante, P \& Aram, J 2003, 'Managers as knowledge generators: The nature of practitioner-scholar research in the nonprofit sector', Nonprofit Management and Leadership, vol. 14, pp. 129-50. https://doi.org/10.1002/nml.26

Schön, D 1983, The reflective practitioner: How professionals think in action, Basic Books, New York.

Stoecker, R, Tryon, E \& Hilgendorf, A 2009, The unheard voices: Community organizations and service learning, Temple University Press, Philadelphia, PA.

Strand, K, Marullo, S, Cutforth, N, Stoecker, R \& Donohue, P 2003, Community-based research and higher education: Principles and practices, Jossey-Bass, San Francisco, CA.

Tuck, E 2009, 'Suspending damage: A letter to communities', Harvard Educational Review, vol. 79, no. 3, pp. 409-28. https://doi.org/10.17763/haer.79.3.n0016675661t3n15

Whitchurch, C 2013, Reconstructing identities in higher education: The rise of third space professionals, Routledge. https:// doi.org/10.4324/9780203098301 